\title{
Axial Gap Studies on the Flow Behavior and Performance of a Counter Rotating Turbine
}

\author{
R. Subbarao ${ }^{\dagger}$ and M. Govardhan \\ Department of Mechanical Engineering, Indian Institute of Technology Madras, Chennai, 600036, India \\ $\dagger$ Corresponding Author Email: rsubbarao@hotmail.com
}

(Received September 12, 2019; accepted February 17, 2020)

\begin{abstract}
A Counter Rotating Turbine (CRT) is an axial flow turbine with a nozzle followed by two rotors that rotate in the opposite direction of each other. Axial gap is an important parameter that affects the performance of turbine stage. Current work contains computationally analyzing the flow physics and performance of CRT with the axial gaps of $15,30,50$ and $70 \%$ of the mean axial chord. Turbine components nozzle and the two rotors are modeled for all the axial gaps of CRT. At nozzle inlet, total pressure is taken as boundary condition and at rotor 2 outlet, mass flow rate is specified. Total pressure, entropy and TKE contours plotted at the inlet and outlet of the blade rows are utilized to analyze the effect of axial gap. Mass flow average distributions of entropy, TKE and relative stagnation pressure loss drawn at rotor 1 and rotor 2 outlets estimate the changes in flow losses with respect to axial gap. The intermediate axial gap of $\mathrm{x} / \mathrm{a}=0.3$ is found to be beneficial for CRT for most of the flow rates. Also, it is found that the smallest and the largest gap cases are showing comparable performance. Thus, results confirm the influence of axial gap on the flow behavior and performance of CRT.
\end{abstract}

Keywords: Counter rotating turbine (CRT); Axial gap; Total pressure; Entropy; TKE; Performance.

\section{NOMENCLATURE}

$\begin{array}{ll}\text { a } & \text { axial chord } \\ \text { ch } & \text { chord } \\ \text { CRT } & \text { Counter Rotating Turbine } \\ \text { LE } & \text { Leading Edge } \\ \text { m } & \text { mass flow rate } \\ \text { PS } & \text { pressure surface }\end{array}$

$\mathrm{r} / \mathrm{r}_{\mathrm{t}} \quad$ radius normalized by tip radius

s blade spacing

SS Suction Surface

TE Trailing Edge

TKE Turbulent Kinetic Energy

$x, y \quad$ distances in usual $\mathrm{x}$ and $\mathrm{y}$ - directions

\section{INTRODUCTION}

Demand for efficiency improvement, weight reduction and consumption of fuel aspect in airline engines have paved the way for Counter Rotating Turbine (CRT), which has two rotors. Traditional axial flow turbine comprises of stators and rotors subsequently positioned one after the other. In CRT, nozzle is followed by two rotors that rotate in the opposite direction of each other. Such arrangement is beneficial, but distinct approach is needed to establish the flow. Specific consideration must be given to the selection of rotational speeds and other flow circumstances. Contemporary computational practices permit us to accomplish this task in less time in order to gain higher turbine performance. CRT can decrease the torque on airliners, resulting in increased maneuverability. Wintucky and Stewart
(1957) studied the work requirements of a two-stage CRT. Ozgur and Nathan (1971) deliberated CRT stage with and without vanes that has equivalent speeds and definite work in both the blades. CRT and the conventional turbine were analyzed by Louis (1985). Ji et al. (2001) examined about the ability of CRT without vanes. These studies revealed the beneficial aspect of CRT. Some of the earlier works studied about parameters like axial gap in axial flow turbines. Venable et al. (1999) as well as Yamada et al. (2009) found advantageous influence of increased axial gap. Instead, Gaetani et al. (2006) and Kikuchi et al. (2008) testified increment in turbine efficiency with decreased axial gap. Since the flow behavior and performance distinction with axial gap is not clear from previous works, it is essential to perform a study that brings out new facts about this limitation. Also, in case of CRT, the effect of axial gap is not 

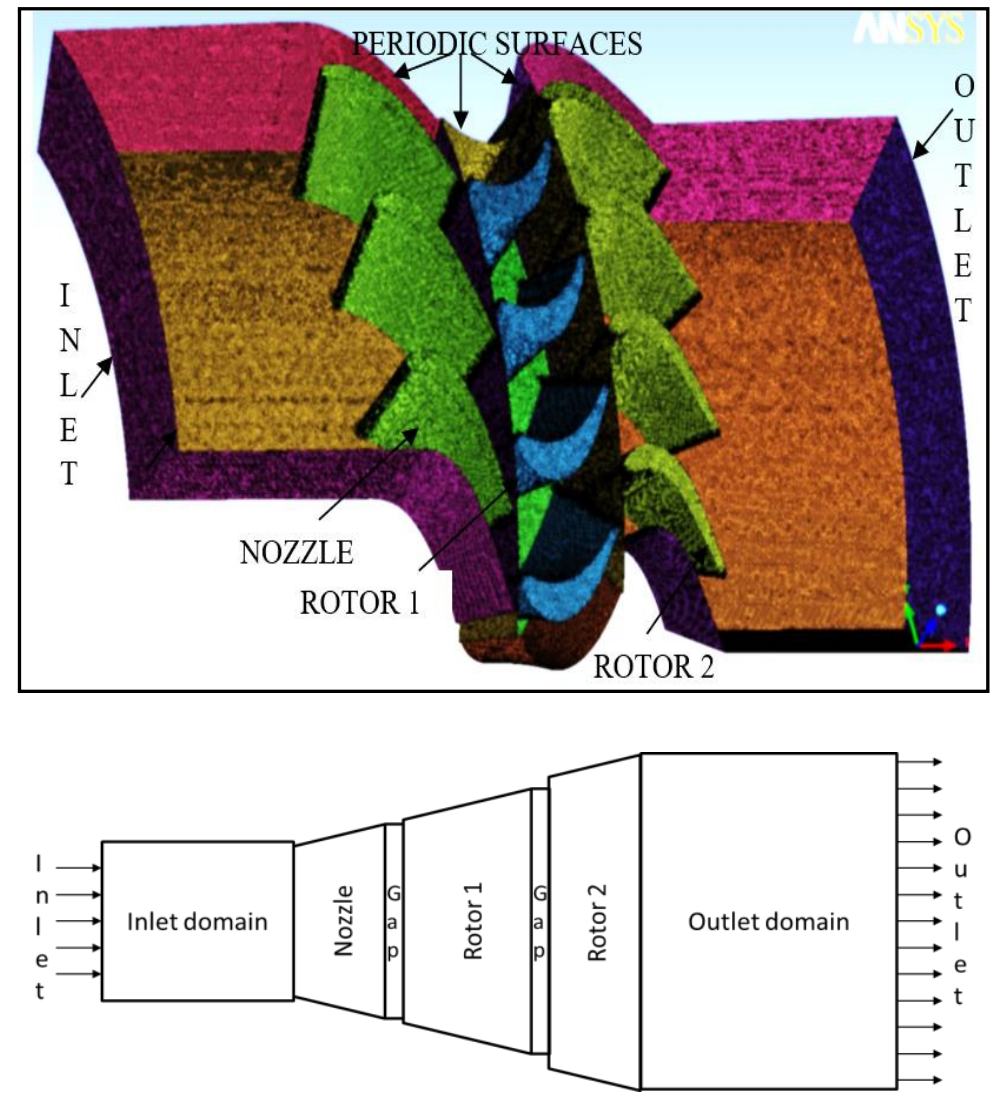

Fig. 1. Computational domain with mesh and schematic of CRT.

dealt with. In the current work, the effect of varying the axial gap is more detailed with respect to the flow physics in blade rows, losses and performance of CRT in a constructive manner. Equivalent mass flow rates are acquired in the range of 0.091 to 0.137 . The $15,30,50$ and $70 \%$ of the average of nozzle and rotor axial chords are taken as axial gaps (Represented as $\mathrm{x} / \mathrm{a}=0.15,0.3,0.5$ and 0.7 ) in the present analysis.

\section{COMPUTATIONAL METHODOLOGY}

CRT stage under study in this work has 22,28 and 28 number of blades of nozzle, rotor 1 and rotor 2 correspondingly. ANSYS $®$ ICEM CFD 14.0 is used for modeling and meshing of the turbine components. As shown in Fig. 1, computational model of CRT contains the blade rows of nozzle, rotor 1 and rotor 2 . It also gives the hint of axial gap between blade rows and schematic of CRT. Table 1 shows the revised geometric details of the profiles acquired from Dring et al. (1987). On both the rotors, tip clearance of $2.28 \mathrm{~mm}$ is provided. Table 2 gives the profile particulars of nozzle and rotor. Identical profile is considered for the two rotors. The axis of revolution is $\mathrm{X}$-axis. Periodic flow is considered here in case of all the blades. In order to keep pitch ratio about 1, three blades of nozzle and four blades of the rotors are considered. For mesh generation, Tetra meshing method is used. It provides a robust smoothening procedure for mesh refinement. Prism meshing is considered with layers near the boundary surfaces for better prediction of the flow close to the wall. Meshing is done with large number of elements adjoining the blade, LE and TE for all the blade rows. Fine mesh aspect can be seen in Fig. 1 for all the three components. Capturing of the boundaries and mesh growth is excellent, as observed. At nozzle inlet, total pressure is selected as boundary condition and at rotor 2 outlet, mass flow rate is specified. Table 3 shows the details of flow parameters. The working fluid is considered as air ideal gas. Frozen rotor interface is used for rotor-stator frame change and rotors' speed is taken as 600 RPM. Turbulence intensity of the flow entering is taken as $1 \%$ in all the configurations. Convergence criteria of target RMS (root mean square) is fixed as $10^{-4}$. Regular k- $\omega$ based SST turbulence model is considered, which captures the flow clearly, both near and away from the surfaces.

\section{GRID INDEPENDENCE STUDY AND VALIDATION}

Grid independence study is done to make sure that results are not changing with change in grid size. Pressure coefficient on the blade is calculated by obtaining the pressure at all the locations of pressure and suction sides of the blade. Pressure coefficient in case of nozzle for four mesh sizes ranging from 3.1 to 4.2 million elements is shown in Fig. 2. It is varying more for coarser mesh. As the mesh size is 
further raised from 3.7 to 4.2 millions, pressure coefficient is not varying. Thus, the optimized mesh of 3.7 million is chosen for nozzle. Similarly, in case of other blades, optimized mesh is chosen as required. Computational results are verified with the results obtained on actual running turbine by Dring et al. (1987). As presented in Fig. 3, pressure coefficient on the rotor blade is used for comparison, which is obtained from the change in blade surface and reference pressures at blade inlet. The pressure coefficient distribution from the present simulation is nicely matching with the experiments on both the pressure and suction surfaces as well as leading and trailing edges. Slight variation on the suction side at $\mathrm{x} / \mathrm{a}=0.4$, may be attributed to the imprecise capturing of sharp edges at midspan.

Table 1 Blade arrangement considered in CRT

\begin{tabular}{|c|c|c|c|}
\hline Parameter & Nozzle & Rotor 1 & Rotor 2 \\
\hline $\begin{array}{c}\text { Number of } \\
\text { blades }\end{array}$ & 22 & 28 & 28 \\
\hline Hub radius (mm) & 610 & 610 & 610 \\
\hline Tip radius (mm) & $762-776$ & $776-790$ & $790-805$ \\
\hline $\begin{array}{c}\text { Tip clearance } \\
(\mathrm{mm})\end{array}$ & 0 & 2.28 & 2.28 \\
\hline
\end{tabular}

Table 2 Nozzle and rotor profiles at midspan

\begin{tabular}{|c|c|c|}
\hline Details & Nozzle & Rotor \\
\hline Axial chord (mm) & 151 & 161 \\
\hline Blade spacing (mm) & 195.11 & 154.9 \\
\hline Space-chord (s/ch) ratio & 0.85 & 0.85 \\
\hline Blade inlet angle & $90^{\circ}$ & $138^{\circ}$ \\
\hline Blade exit angle & $21.42^{\circ}$ & $25.97^{\circ}$ \\
\hline Stagger angle & $49.56^{\circ}$ & $31.59^{\circ}$ \\
\hline Deflection angle & $68.58^{\circ}$ & $111.85^{\circ}$ \\
\hline
\end{tabular}

Table 3 Flow parameters used in this work

\begin{tabular}{|c|c|}
\hline Parameter & Value \\
\hline Temperature at inlet $(\mathrm{K})$ & 480 \\
\hline Inlet total pressure $(\mathrm{Pa})$ & $1.35 \times 10^{5}$ \\
\hline Equivalent flow rate & $0.091-0.137$ \\
\hline Working fluid & Air ideal gas \\
\hline Inlet turbulence $(\%)$ & 1 \\
\hline
\end{tabular}

\section{RESULTS AND DISCUSSION}

The purpose of the current work is to study the effect of axial gap on the flow physics and performance of the CRT stage. To describe the flow, variables like total pressure, entropy and Turbulent Kinetic Energy (TKE) are considered. Planes are taken at a distance of $\mathrm{x} / \mathrm{a}=0.075$, before and after the blades. Mass average values are taken for analysis of loss and performance at the respective planes. Hub-to-tip variations at these planes are plotted in $\mathrm{x}-\mathrm{y}$ graphs. Radius along the hub to tip direction is normalized by radius at the tip and is denoted by $\mathrm{r} / \mathrm{r}_{\mathrm{t}}$. In the contours drawn at blade exits, tangential distance (y) is normalized with blade spacing (s) and is represented as $\mathrm{y} / \mathrm{s}$. The values of $\mathrm{y} / \mathrm{s}$ range from 0 to 1 , that represent the mid passage values of the two subsequent blades. To compare the values of performance and various flow parameters for different configurations and circumstances normalization is done. Mass flow rate is normalized based on inlet conditions and is referred as equivalent mass flow rate in this work. Pressures and entropy are normalized by turbine inlet pressure and gas constant respectively. TKE is normalized with square of speed. Contours drawn along the transverse plane and hub-to-tip plots reveal the actual scenario of the flow in the turbine stage. Relative stagnation pressure loss and performance aspects with axial gap are discussed in the end.

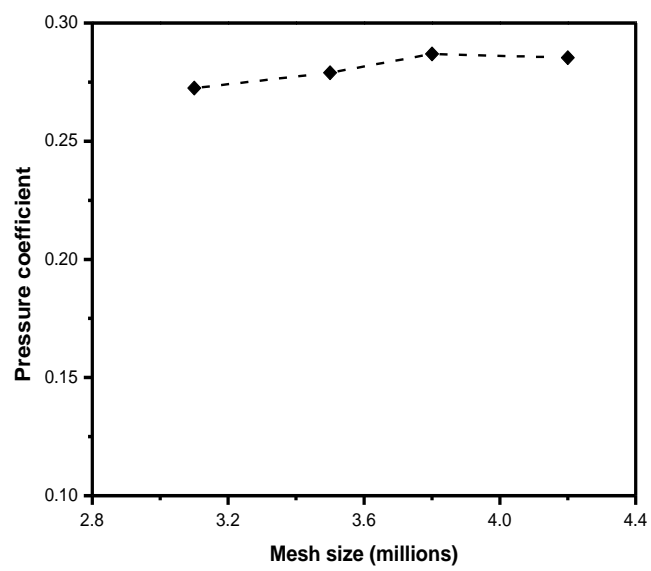

Fig. 2. Grid independence study of nozzle.

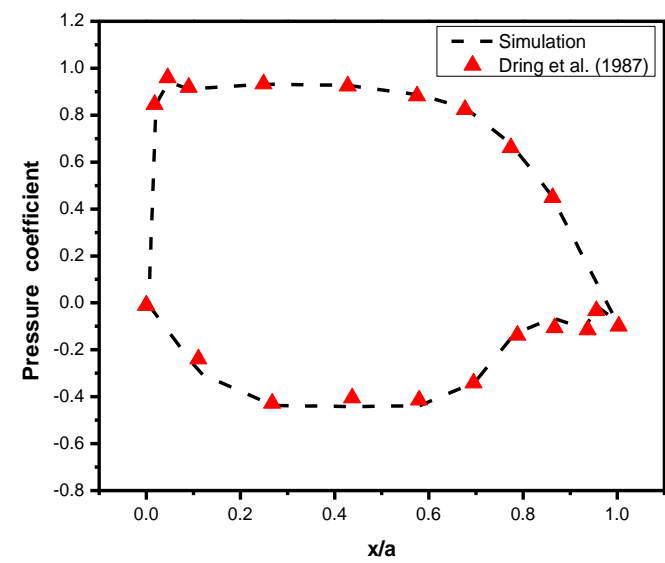

Fig. 3. Validation using pressure coefficient in rotor 1 blade. 

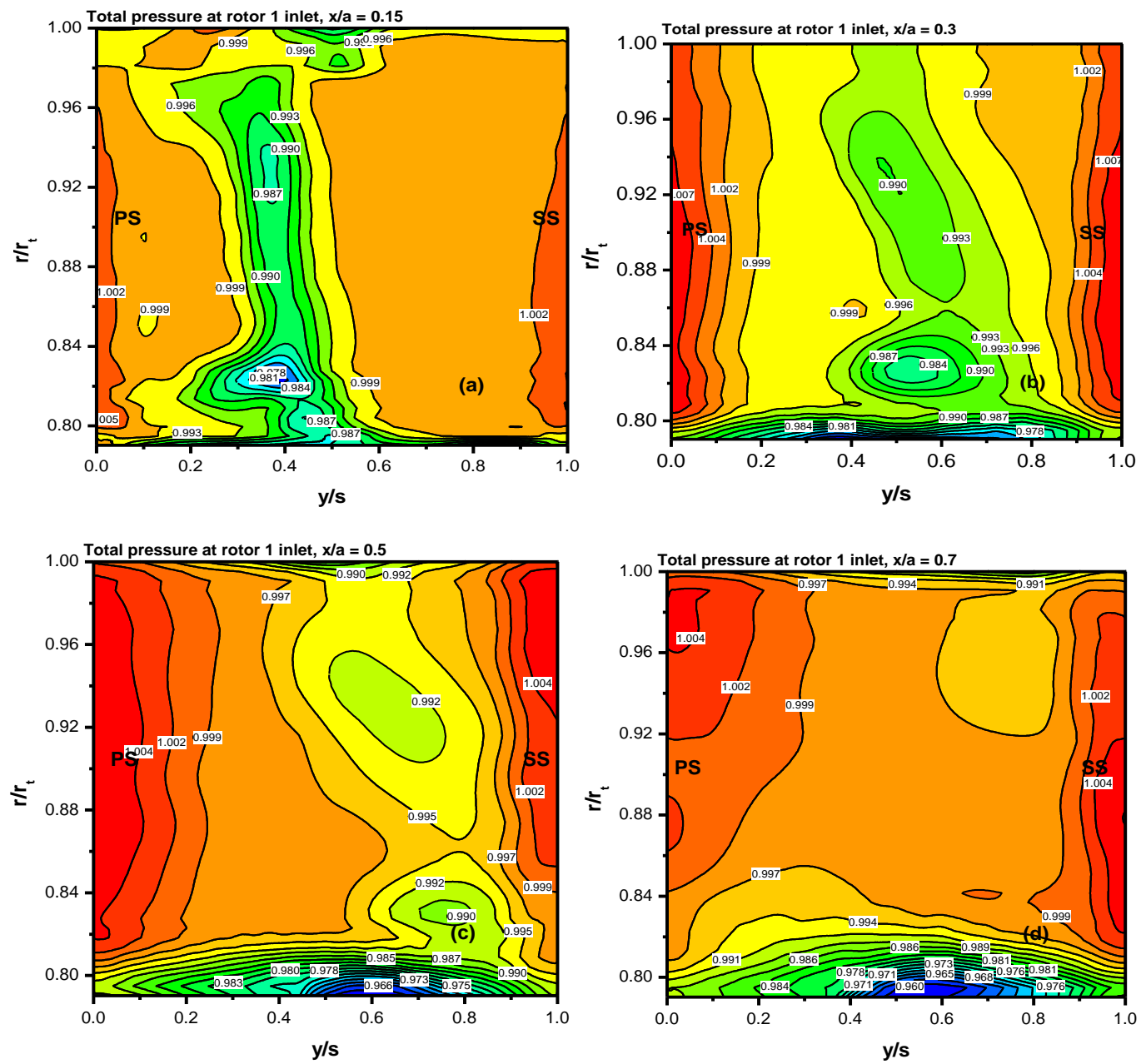

Fig. 4. Total pressure at rotor 1 inlet with axial gap.

\subsection{Total Pressure at the Inlet of Rotors}

The variation of total pressure is shown in Fig. 4 at rotor 1 inlet. As presented in the total pressure contour, spread of nozzle exit wake to the inlet region of rotor 1 is clearly detected in the lower axial gap case of $\mathrm{x} / \mathrm{a}=0.15$. As the gap is increased, wake effect gets reduced and also change in the position of the wake is observed. This is because of the space requirement by the flow in order to get mixed completely. But, the hub side pressure losses are slightly increasing with gap, which are observed in $\mathrm{x} / \mathrm{a}=0.3,0.5$ and 0.7 . In $x / a=0.15$, low pressure region is observed near the tip side. For $\mathrm{x} / \mathrm{a}=0.3$, the total pressure variation is not observed in the tip region when compared with higher gaps, which suggests that wake is mixing properly near the tip and this effect is less for the rest of the span. In $\mathrm{x} / \mathrm{a}=0.5$ and 0.7 , tip side pressure loss regions are observed, which are less in magnitude when compared to $\mathrm{x} / \mathrm{a}=$ 0.15 . At rotor 2 inlet, low pressure section is witnessed for $\mathrm{x} / \mathrm{a}=0.15$ on the suction side as shown in Fig. 5. The position of this low pressure region is changing as the gap is increased, playing a crucial role in affecting rotor performance. On the pressure side, pressures are reducing with gap from $\mathrm{x} / \mathrm{a}=0.15$ to 0.3 . Pressures are high for $\mathrm{x} / \mathrm{a}=$ 0.5 and decrease as the gap is raised to 0.7. From the pressure contours, it is clear that the fluid from rotor 1 wake region is moving towards the suction side of the rotor 2 in case of $x / a=0.15$. These wakes increase non-uniformity of pressure and flow incidence near rotors. With increased axial gap, the tendency of the wake mixing changes both these aspects.

\subsection{Entropy and TKE at the Inlet of Rotors}

Loss regions are represented in the form of entropy contours at the inlet of rotors in Fig. 6. High entropy values are observed in the wake region for $\mathrm{x} / \mathrm{a}=0.15$ and 0.3 . These losses extend up to the tip near the leading edge of rotor 1 . Extent of losses over the span reduced as the gap is increased. On the other hand, as the gap is increased to $\mathrm{x} / \mathrm{a}=0.5$ and 0.7 , hub side losses strengthen, when compared to lower gaps of $\mathrm{x} / \mathrm{a}=$ 0.15 and 0.3 . Entropy is more on the suction side of rotor 2 for $\mathrm{x} / \mathrm{a}=0.15$ as shown in Fig. 7. This loss region shifts towards the LE region of rotor 2 as the gap is increased with change in magnitude, affecting the performance. Entropy contours 

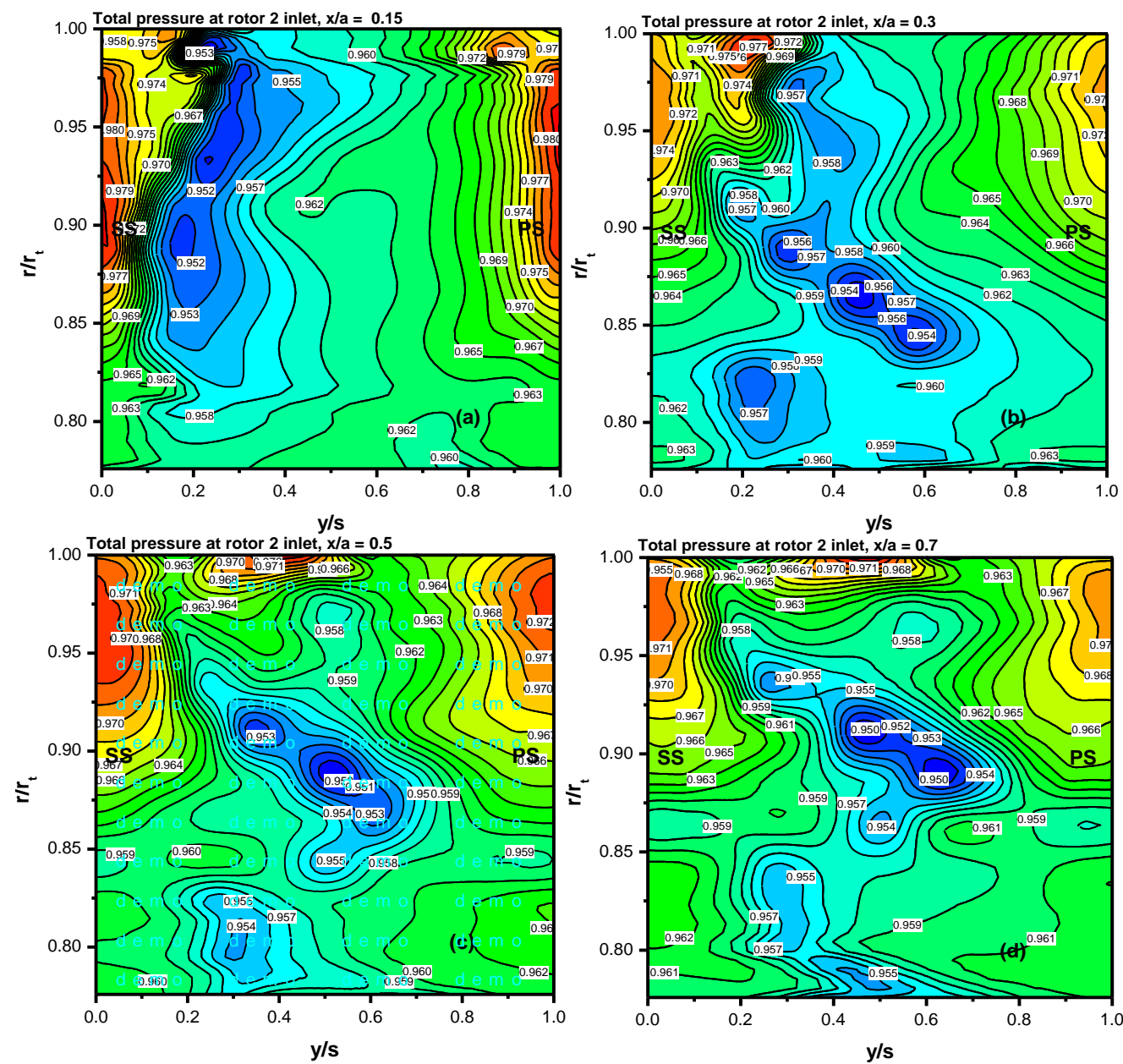

Fig. 5. Total pressure at rotor 2 inlet with axial gap.

confirm that losses are concentrated more near the tip and less in the passage. Losses are equally less near to the hub in all the axial gap cases. This is due to low secondary losses near the hub compared to the passage and tip side losses that get transmitted from the upstream rotor. TKE values vary with axial gap as seen in the contours drawn in Figs. 8 and 9. Flow turbulence near the leading edge of rotor 2 is changing with axial gap, affecting the rotor 2 performance and that of turbine stage. Figure 8 shows the presence of high TKE near the leadingedge region of rotor 1 in $\mathrm{x} / \mathrm{a}=$ 0.15 , which gets reduced as the gap is increased. The hub side TKE values are less for $\mathrm{x} / \mathrm{a}=0.15$ when compared to other gaps. Contours drawn at rotor 1 inlet confirm that change in axial gap caused change in the rotor upstream flow. Similarly, high TKE is detected at rotor 2 inlet as shown in Fig. 9. On the suction side passage, more TKE is observed with $\mathrm{x} / \mathrm{a}$ $=0.15$. As seen in entropy contours, the high TKE region shifts to the LE of the rotor with increased gap. Fluid enters the second rotor with more turbulence, because of which, TKE values are more at the rotor 2 inlet when compared to the rotor 1 inlet, which affects the performance of rotor 2. High turbulence region is created in the intermediate spacing of rotor 1 and rotor 2 as the fluid gets engulfed between the oppositely rotating rotors.

\subsection{Hub-to-Tip Variation with Axial Gap}

In this section, hub-to-tip variation of flow parameters is deliberated at the rotor exits. Figure 10 shows the mass averaged radial distribution of total pressure. At rotor 1 outlet, variation of total pressure is observed from hub to tip as shown in Fig. 10(a). Throughout the span, pressures are more for the smallest gap of $\mathrm{x} / \mathrm{a}=0.15$ and low for the highest gap of $\mathrm{x} / \mathrm{a}=0.7$. For the intermediate gaps, the variation is less compared to the lower and higher axial gaps. Hub side pressures are low when compared to the tip as wake is more dominant. At the outlet of rotor 2, variation of pressure in the span wise direction is less for all the axial gap cases up to $70 \%$ of the span as shown in Fig. 10(b). Because of the combined tip clearance effect, which varies with gap tip side pressures drop more, when compared to the rest of the span.

Entropy variation from hub to tip at the outlet of rotors is shown in Fig. 11. As shown in Fig. 11 (a), entropy is less for lower gaps from $20 \%$ of the span to the tip at rotor 1 outlet. It means that hub side 

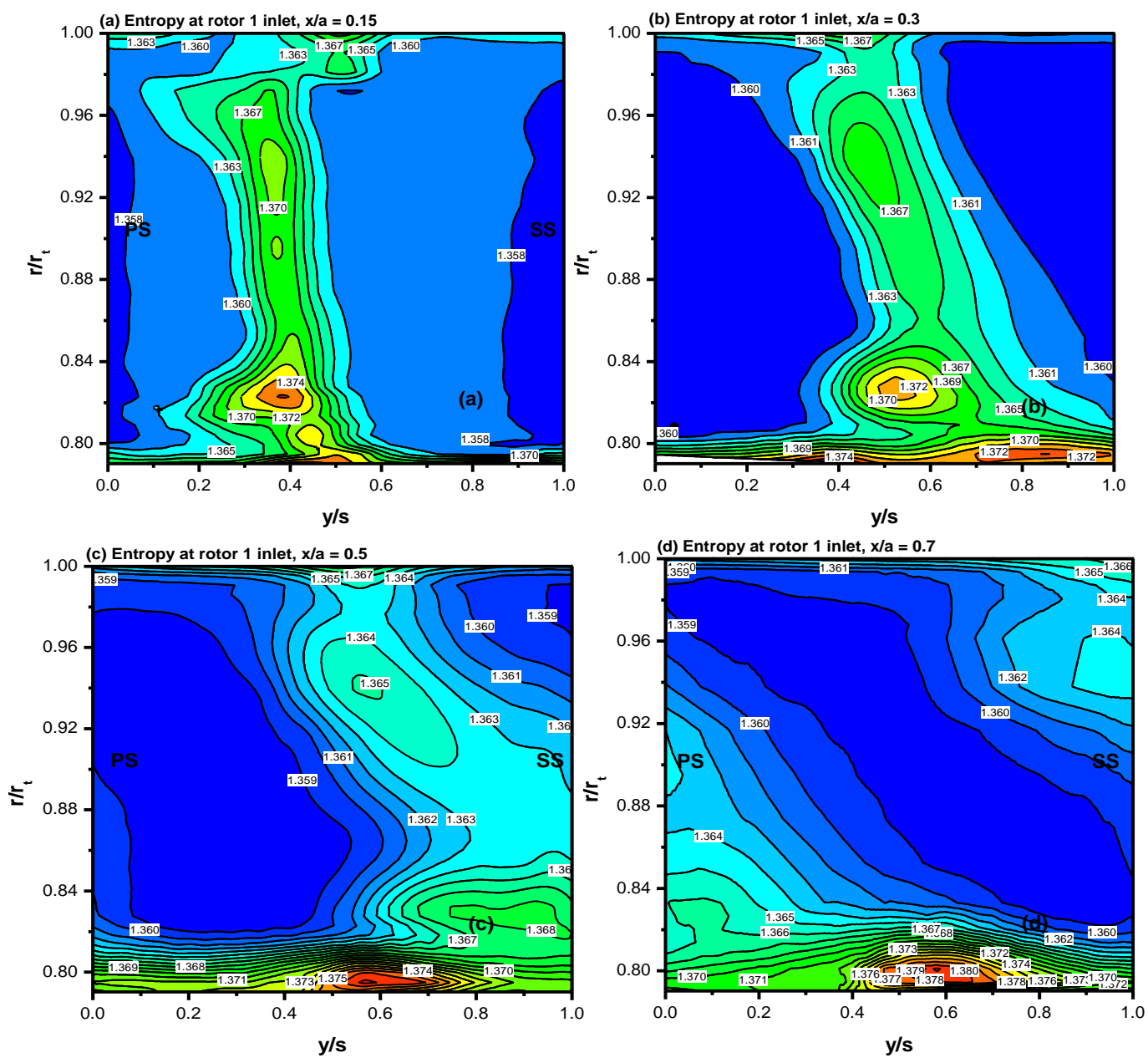

Fig. 6. Entropy at rotor 1 inlet with axial gap.

losses are more for the smaller gaps and less for higher gaps. This is due to availability of less space for the flow near the hub, before entering into the second rotor passage. Clearly, entropy variation from hub to tip is less for $x / a=0.3$. At the outlet of rotor 2 , tip side entropy values are more for $\mathrm{x} / \mathrm{a}=0.7$ and decrease with axial gap as shown in Fig. 11(b). For the intermediate axial gap of $\mathrm{x} / \mathrm{a}=0.3$, entropy is lower up to the midspan section. Entropy values for $\mathrm{x} / \mathrm{a}=0.3$ are slightly higher than $\mathrm{x} / \mathrm{a}=0.15$ above the midspan and are comparable to $\mathrm{x} / \mathrm{a}=0.5$ near the tip. This reveals the advantageous feature of the intermediate axial gap, for which entropy values are less at the exit of CRT. At the outlet of rotor 1, for smaller gaps of $\mathrm{x} / \mathrm{a}=0.15$ and 0.3 , TKE is less throughout the span except at the tip region as shown in Fig. 12(a). More variation of TKE is observed with increased gap at the mid-span when compared to hub and tip. TKE is more throughout the span for the highest gap of $\mathrm{x} / \mathrm{a}=0.7$ and decreases as the gap is reduced. This identifies the significance of choosing a certain gap that flow is correctly guided and improved mixing takes place at the intermediate zone before entering the second rotor. Hub-to-tip variation of TKE at rotor 2 outlet is shown in Fig. 12(b). TKE is more for $\mathrm{x} / \mathrm{a}=0.7$ over the entire span except at the hub, where TKE is more for $\mathrm{x} / \mathrm{a}=0.15$. Near the tip, TKE is less and same for $\mathrm{x} / \mathrm{a}=0.3$ and 0.5 . Similarly, near the hub and over the most of the span, $\mathrm{x} / \mathrm{a}=0.3$ configuration showed low TKE values at the exit of second rotor. Accordingly, TKE plots support losses in the turbine stage with respect to axial gap.

\subsection{Losses and Performance with Axial Gap}

As discussed in the previous sections, it is clearly implicit that axial gap plays an important role in the flow pattern of CRT. This section deals with loss and performance aspects with change in axial gap. In case of $x / a=0.15$, relative stagnation pressure loss is less in rotor 1 as shown in Fig. 13(a). As the gap is increased beyond $\mathrm{x} / \mathrm{a}=0.3$, pressure losses vary only little except for higher flow rates. As seen in Fig. 13 (b), relative stagnation pressure loss is more for $\mathrm{x} / \mathrm{a}=0.15$ in rotor 2 . Pressure losses are less for the CRT configuration with the intermediate axial gap cases of $\mathrm{x} / \mathrm{a}=0.3$ and 0.5 in case of all the flow rates except for 0.137 . Variation is less in rotor 2 for $\mathrm{x} / \mathrm{a}=$ 0.5 and 0.7 for all the flow rates. This is supported by the reduced steepness of the loss curve after $30 \%$ 

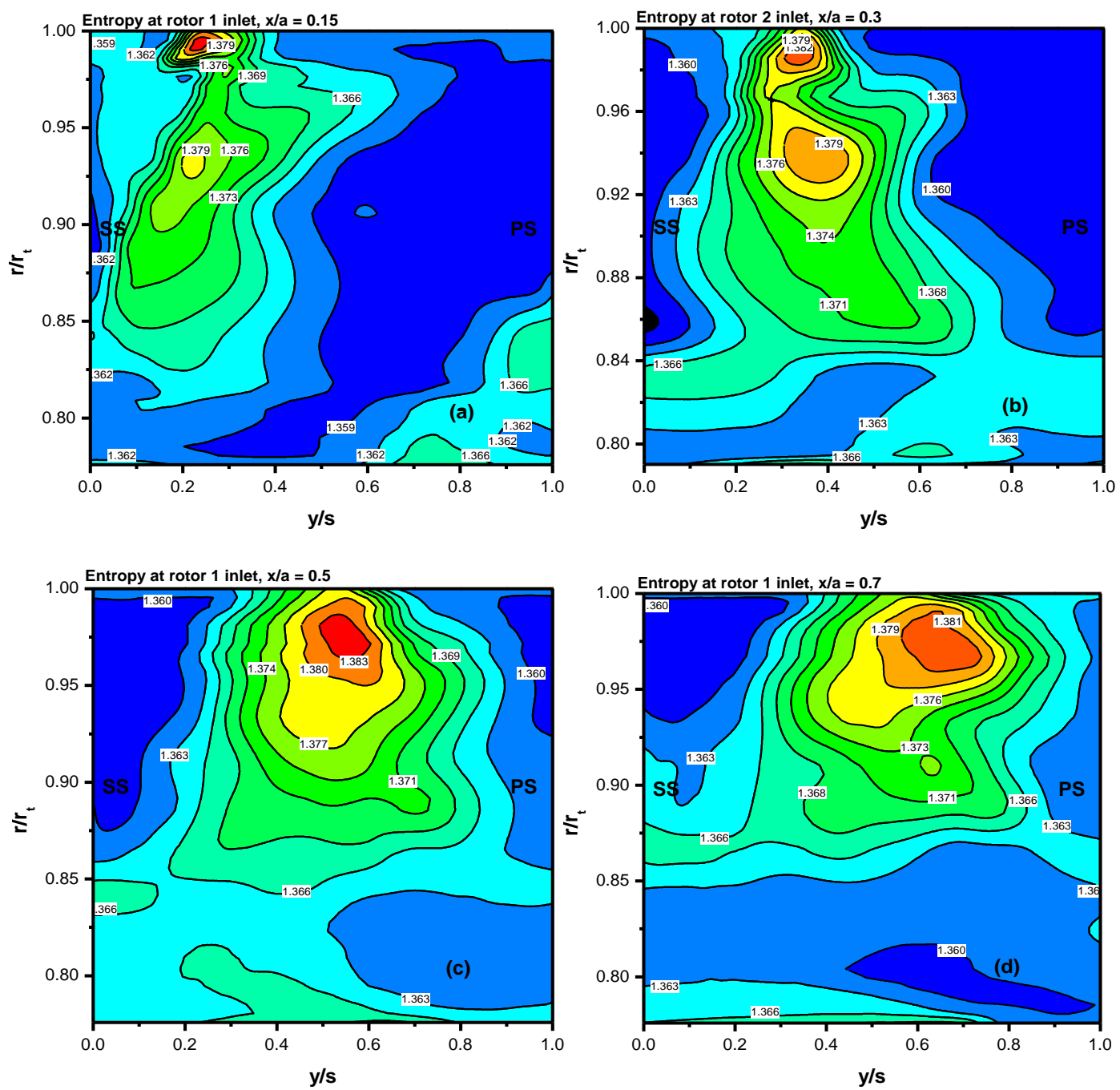

Fig. 7. Entropy at rotor 2 inlet with axial gap.

gap in case of rotor 1. Plots suggest that increment of gap up to $\mathrm{x} / \mathrm{a}=0.3$ is advantageous in rotor 2 and significant in rotor 1. Efficiency is considered as the ratio of power output obtained from rotors to the input obtained from stage enthalpy drop. Power output $\left(\mathrm{P}_{\text {output }}\right)$ is obtained from the torque attained from the two rotors. Efficiency is then calculated by $\eta=\frac{P_{\text {output }}}{(m \times \Delta H)}$, where $\Delta \mathrm{H}$ is change in enthalpy and $\mathrm{m}$ is mass flow rate.

Figure 14 shows the efficiency of CRT stage, rotor 1 and rotor 2 with regard to axial gap. As the gap is increased, efficiency increases up to $\mathrm{x} / \mathrm{a}=0.3$, after which, it remains same in rotor 2 as shown in Fig. 14(b). This is witnessed in all the flow rates except 0.137 . In case of rotor 1 as well, $30 \%$ gap proved to be constructive, as the performance has not changed considerably beyond this position as shown in Fig. 14(a). Overall efficiency of CRT is less for $\mathrm{x} / \mathrm{a}=0.15$ as shown in Fig. 14(c). As the gap is increased to $\mathrm{x} / \mathrm{a}$ $=0.3$, efficiency becomes maximum as losses in the CRT stage are less as discussed earlier. Beyond this, efficiency of CRT reduced. Accordingly, for the present configuration it is beneficial to have an axial gap of $30 \%$ between nozzle - rotor 1 and rotor 1 - rotor 2. This is in agreement with the measurements in a subsonic high pressure turbine obtained by Gaetani et al. (2006). Results also indicate that the efficiencies for the smallest gap, $\mathrm{x} / \mathrm{a}=0.15$ and the largest gap, $\mathrm{x} / \mathrm{a}=0.7$ are comparable. Present study thus confirms the advantageous aspect of changing the axial gap in case of CRT stage. For $\mathrm{x} / \mathrm{a}=0.3$, the losses are less and efficient is more. Depending on the design of turbine stage, advantageous axial gap can be identified.

\section{CONCLUSIONS}

In this work, the influence of axial gap on the flow behavior and performance of counter rotating turbine is studied computationally. Axial gaps of $15,30,50$ and $70 \%$ of the average of nozzle and rotor axial chords are considered. Nozzle, rotor 1 and rotor 2 are computationally modeled for all the axial gaps. Total pressure, entropy and TKE are used as parameters for understanding the flow pattern. Relative stagnation pressure and loss along with performance aspects are obtained for all the axial gap cases. Grid independence study and validation are carried out. The pressure coefficient distribution from the present 

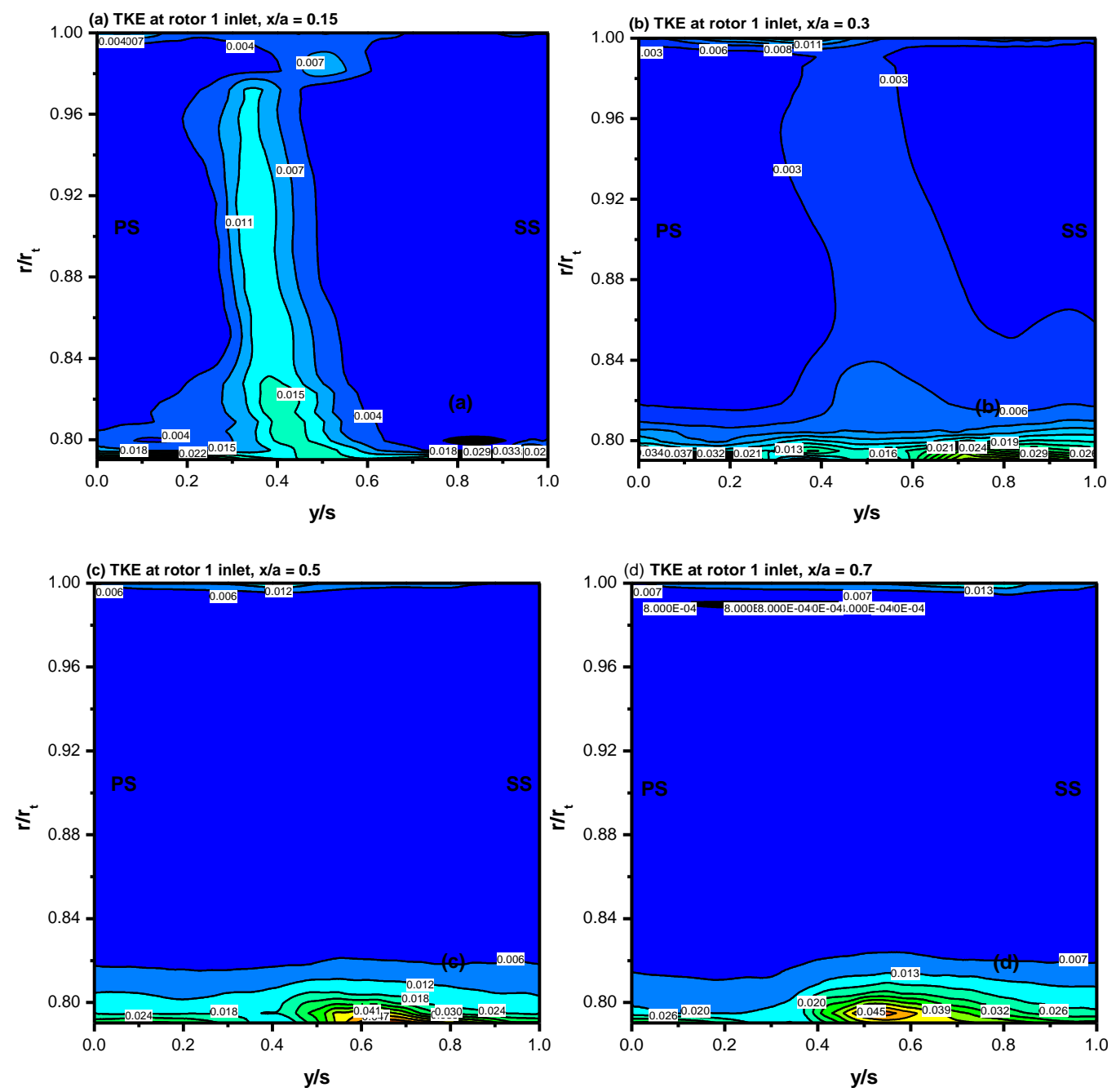

Fig. 8. TKE at rotor 1 inlet with axial gap.

simulation is well matching with the experiments on both the pressure and suction surfaces as well as leading and trailing edges. From the pressure contours, it is clear that the tendency of the wake mixing is changing with axial gap. Fluid enters the second rotor with more turbulence, because of which, TKE values are more at the rotor 2 inlet when compared to the rotor 1 inlet, which affects the performance of rotor 2. Hub-to-tip variation of the flow parameters at the rotor exits is also deliberated. Pressure losses are less for the CRT configuration with the intermediate axial gap cases of $\mathrm{x} / \mathrm{a}=0.3$ and 0.5 in case of all the flow rates except for 0.137 . Entropy and TKE contours approve that flow and turbulence losses are less in rotors for the case of intermediate axial gap. Efficiency changes noticeably with axial gap. The intermediate gap case of $\mathrm{x} / \mathrm{a}=0.3$ has the highest efficiency for most of the flow rates. Also, the performance of CRT in case of the smallest gap, $\mathrm{x} / \mathrm{a}=0.15$ and the largest gap, $\mathrm{x} / \mathrm{a}$ $=0.7$ are comparable. It is clear that $30 \%$ axial gap between nozzle - rotor 1 and rotor 1 - rotor 2 interfaces would be beneficial for the CRT stage. Thus, results confirm the effect of axial gap on CRT performance. Also, high pressure stage (first rotor) is a major contributor in obtaining the overall performance of CRT, which is true at all mass flow rates and axial gaps.

\section{REFERENCES}

Dring, R. P., H. D. Joslyn and M. F. Blair (1987). The effect of inlet turbulence and rotor/stator interactions on the aerodynamics and heat transfer of large scale rotating turbine model. NASA Report, CR 179469.

Gaetani, P., G. Persico, V. Dossena and C. Osnaghi (2006). Investigation of the flow field in a hp turbine stage for two stator-rotor axial gaps, Part I-3D time-averaged flow field. ASME Turbo Expo 2006: Power for Land, Sea, and Air, Spain. ASME paper, GT 2006-90553, 659-668.

Ji, L. C., X. B. Quan, L. Wel and J. Z. Xu (2001). A vaneless counter rotating turbine design towards limit of specific work ratio. ISABE paper 2001 1062.

Kikuchi, M., K. Funazaki, K. Yamada and H. Sato (2008). Detailed studies on aerodynamic performance and unsteady flow behaviors of a 
R. Subbarao and M. Govardhan / JAFM, Vol. 13, No. 5, pp. 1515-1525, 2020.
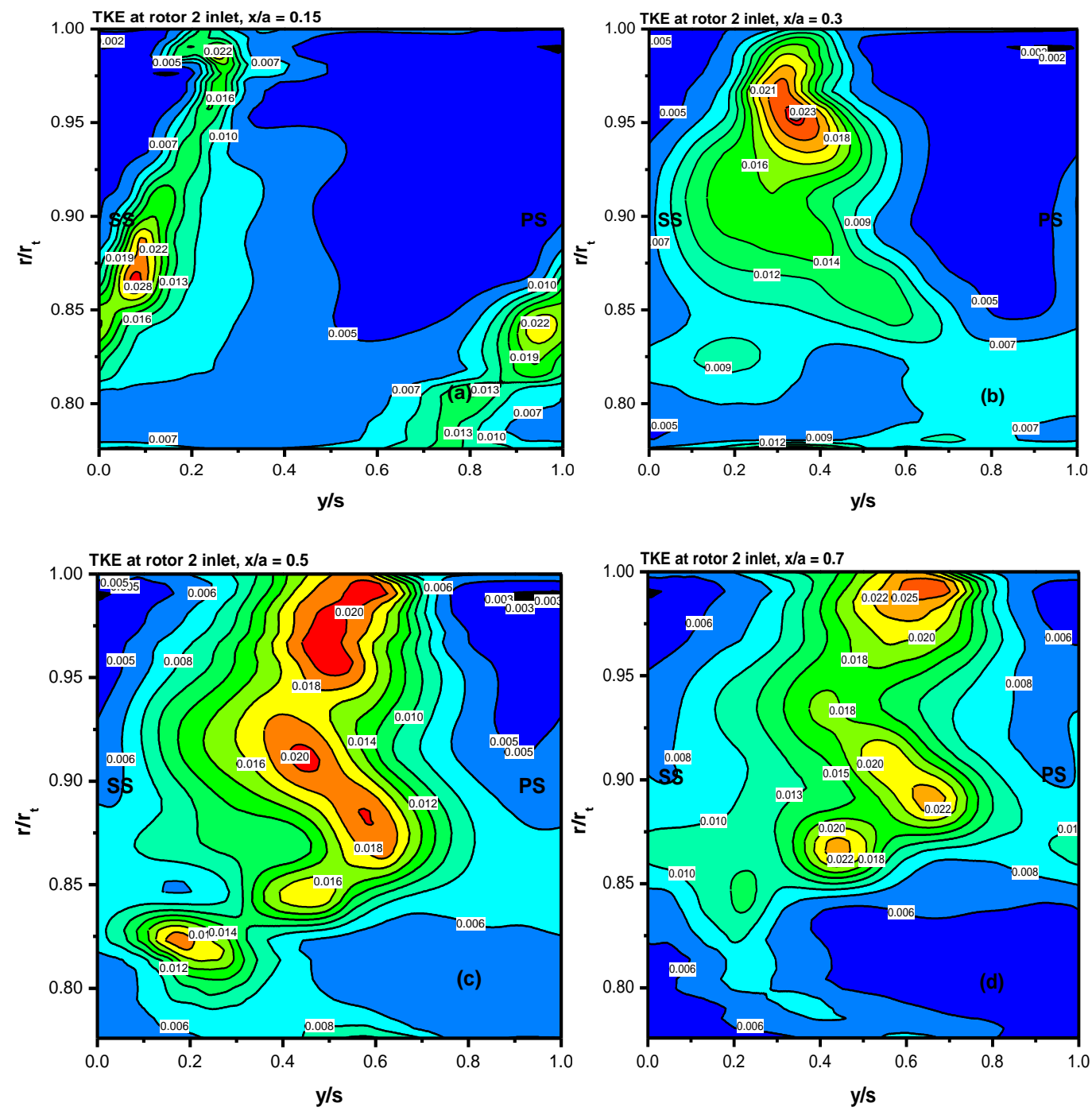

Fig. 9. TKE at rotor 2 inlet with axial gap.
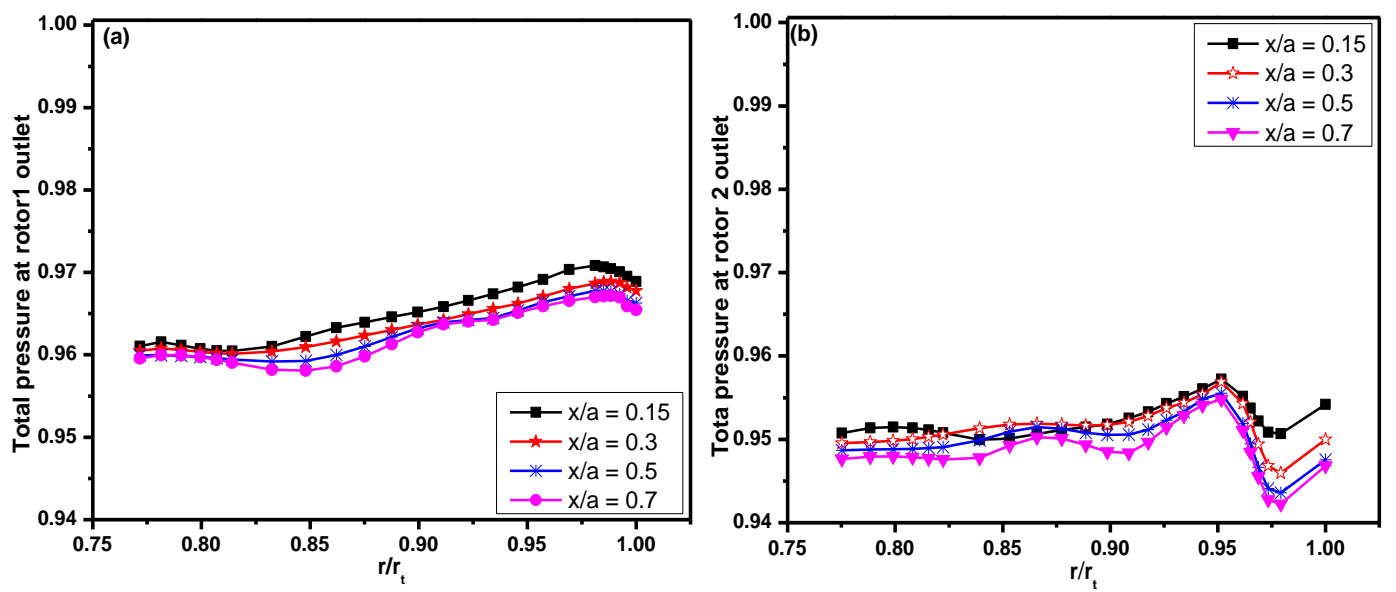

Fig. 10. Total pressure at the exit of rotors with axial gap. 

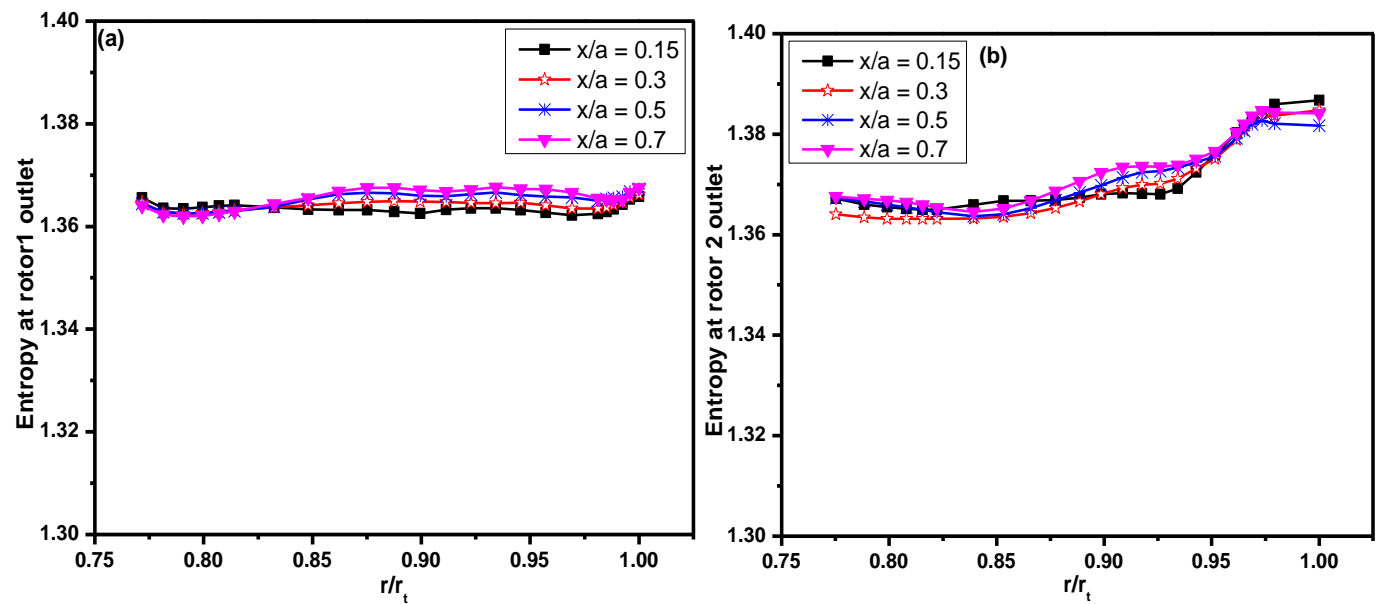

Fig. 11. Entropy at the exit of rotors with axial gap.
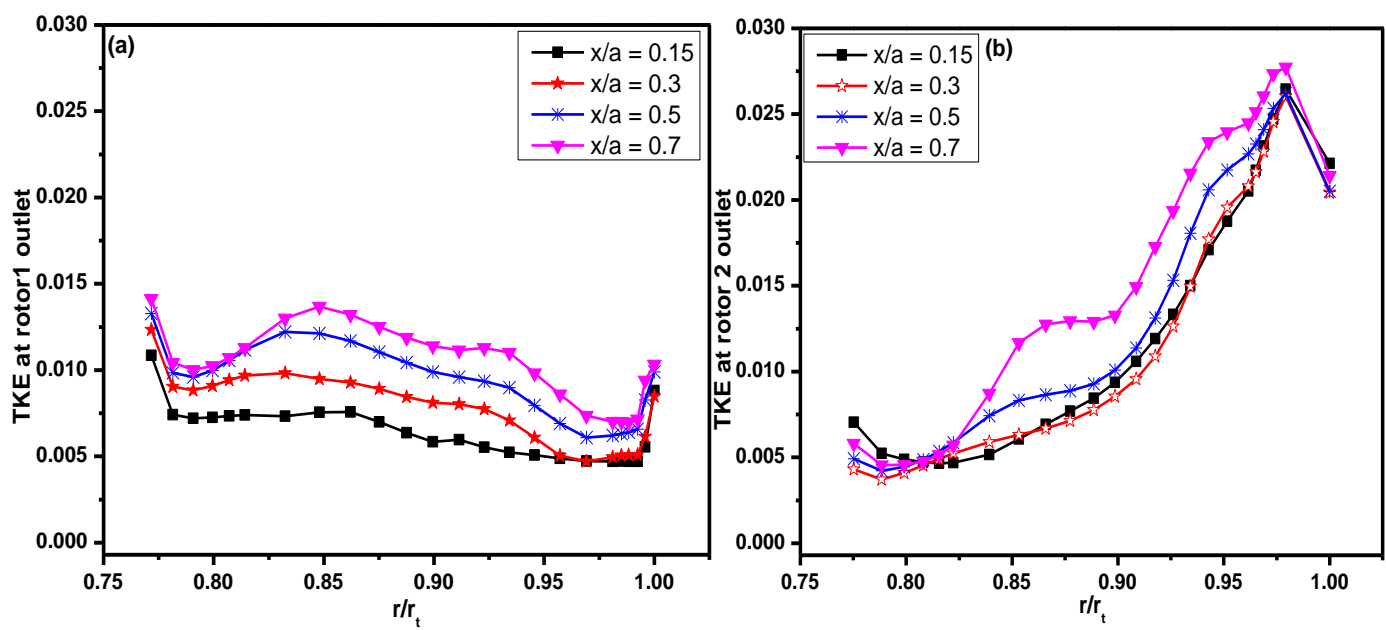

Fig. 12. TKE at the exit of rotors with axial gap.
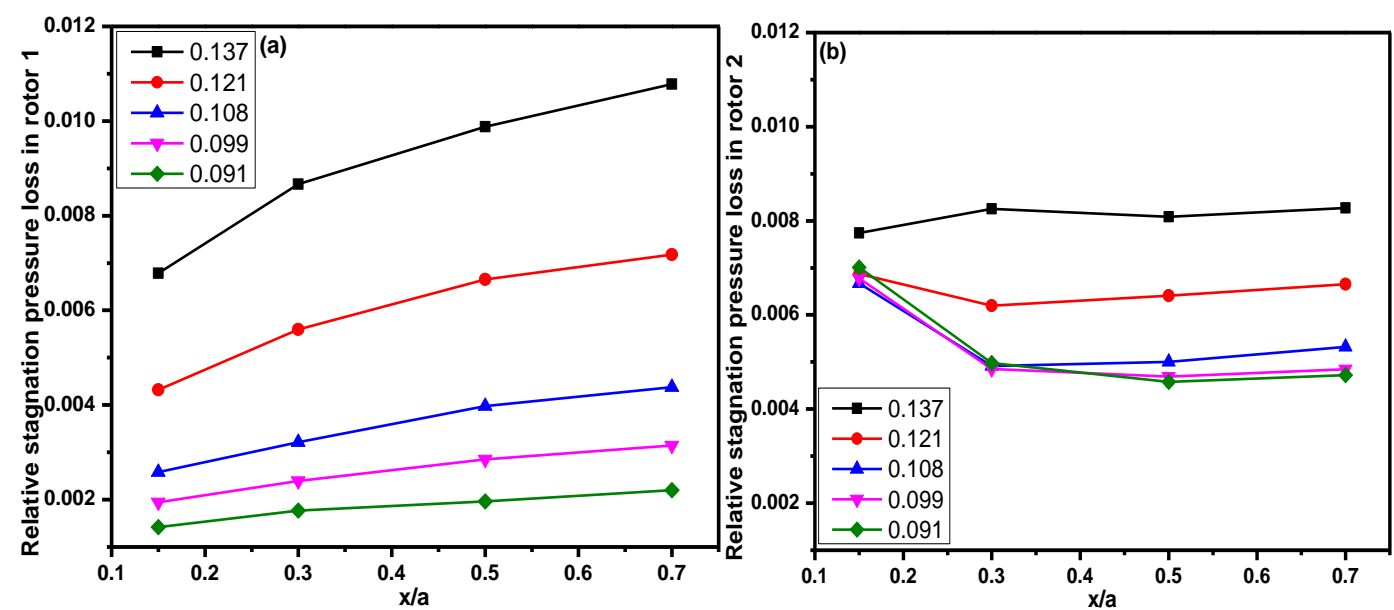

Fig. 13. Relative stagnation pressure loss in rotor 1 and rotor 2 with axial gap. 

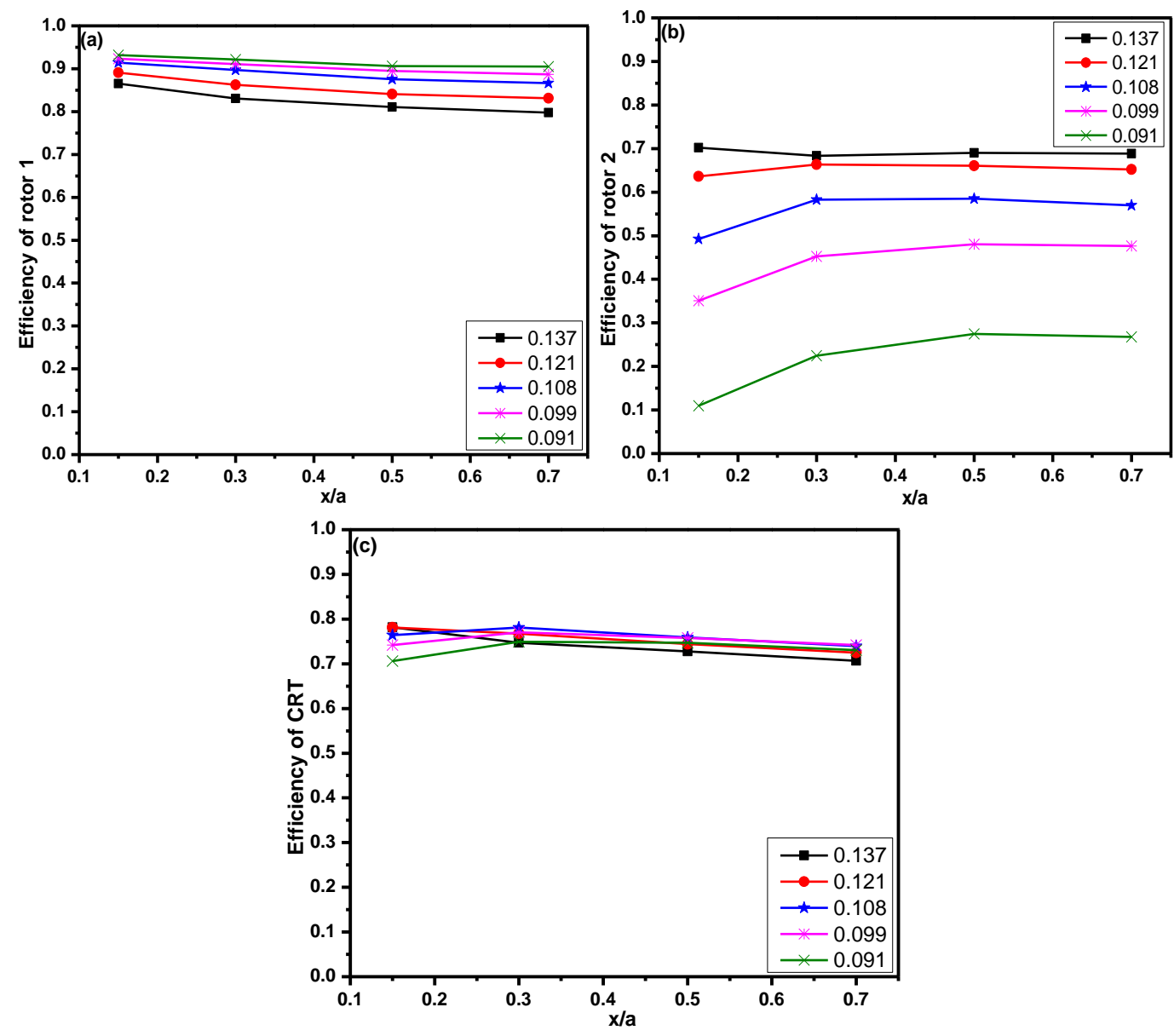

Fig. 14. Efficiency of rotor 1, rotor 2 and CRT with respect to axial gap.

single turbine stage with variable rotor-stator axial gap. International Journal of Gas Turbine, Propulsion and Power Systems, 2(1), 30-37.

Louis, J. F. (1985). Axial flow contra-rotating turbines. ASME paper, 85-GT-218.

Ozgur, C. and G. K. Nathan (1971). Study of contrarotating turbines based on design efficiency. Journal of Basic Engineering, 93, 395-404.

Venable, B. L., R. A. Delaney, J. A. Busby, R. L. Davis, D. J. Dorney, M. G. Dunn, C. W. Haldeman and R. S. Abhari (1999). Influence of vane-blade spacing on transonic turbine stage aerodynamics: Part I - time-averaged data and analysis. Journal of Turbomachinery, 121, 663672.

Wintucky, W. T. and W. L. Stewart (1957). Analysis of two-stage counter-rotating turbine efficiencies in terms of work and speed requirements. NACA Report, RM E57L05.

Yamada, K., K. Funazaki, M. Kikuchi and H. Sato (2009). Influences of axial gap between blade rows on secondary flows and aerodynamic performance in a turbine stage. ASME Turbo Expo 2009: Power for Land, Sea, and Air, Florida. ASME paper, GT 2009-59855, 10391049. 